\title{
Long-term trends in aquatic ecosystem bioassessment metrics are not influenced by sampling method: empirical evidence from the Niobrara River
}

\author{
Lusha M. Tronstad ${ }^{1, *}$ and Scott Hotaling ${ }^{2}$ \\ ${ }^{1}$ Wyoming Natural Diversity Database, University of Wyoming, 1000 East University Avenue, Laramie, WY 82071, USA \\ ${ }^{2}$ Department of Biology, University of Kentucky, 101 Thomas Hunt Morgan Building, Lexington, KY 40506, USA
}

\begin{abstract}
Choosing an aquatic invertebrate sampling method for biomonitoring depends upon study goals, resources, and ecosystem conditions. In this study, we compared two methods that are widely used in stream ecology, but have not been directly compared: Hester-Dendy (HD) and Hess sampling. Hester-Dendy sampling uses artificial substrate that invertebrates colonize over a specific period of time. In contrast, Hess samplers surround a fixed area of natural substrate with a net. To compare approaches, we combined 5 years of simultaneous HD and Hess data collection (2010-2014) from the Niobrara River with a 14-year (1996-2009) historical HD data set for the same study sites. We used this full 19-year data set to assess how ecosystem health has changed in the Niobrara River over time, while also testing the influence of HD versus Hess data (2010 2014) on historical trends (1996-2009). Our results showed that HD samples are more taxonomically variable and bias bioassessment metrics because they collect more sensitive taxa versus Hess sampling. However, when combined with the 1996-2009 HD data set, both recent HD and Hess data sets recovered the same trend of declining ecosystem health in the Niobrara River. These results provide empirical evidence that even when historical HD data are combined with recent Hess data, long-term bioassessment trends remain unchanged despite more accurate perspectives of invertebrate assemblages being collected.
\end{abstract}

Keywords: biodiversity / stream ecology / biomonitoring / Hester-Dendy sampling / Hess sampling

Résumé - Les tendances à long terme des mesures de bioévaluation des écosystèmes aquatiques ne sont pas influencées par la méthode d'échantillonnage : des preuves empiriques de la rivière Niobrara. Le choix d'une méthode d'échantillonnage des invertébrés aquatiques pour la biosurveillance dépend des objectifs de l'étude, des ressources et des conditions de l'écosystème. Dans cette étude, nous avons comparé deux méthodes largement utilisées dans l'écologie des rivières, mais n'ont pas été directement comparées: échantillonnage Hester-Dendy (HD) et Hess. L'échantillonnage de Hester-Dendy utilise un substrat artificiel que les invertébrés colonisent sur une période de temps spécifique. En revanche, les échantillonneurs Hess entourent une surface fixe de substrat naturel avec un filet. Pour comparer les approches, nous avons combiné cinq années de collecte simultanée de données HD et Hess (2010-2014) de la rivière Niobrara avec un ensemble historique de données HD de 14 ans (1996-2009) pour les mêmes sites d'étude. Nous avons utilisé ce jeu de données complet de 19 ans pour évaluer la façon dont la santé des écosystèmes a changé dans la rivière Niobrara au fil du temps, tout en testant l'influence des données HD versus Hess (20102014) sur les tendances historiques (1996-2009). Nos résultats ont montré que les échantillons HD sont plus variables taxonomiquement et leurs valeurs biaisées, car ils recueillent des taxons plus sensibles par rapport aux prélèvements de Hess. Cependant, lorsqu'ils ont été combinés avec l'ensemble de données HD de 1996-2009, les deux derniers ensembles de données HD et Hess ont retrouvé la même tendance à la baisse de la santé des écosystèmes dans la rivière Niobrara. Ces résultats fournissent des preuves empiriques que, même lorsque les données HD historiques sont combinées avec les données récentes de Hess, les tendances de bioévaluation à long terme restent inchangées malgré des perspectives plus précises des assemblages d'invertébrés collectés.

Mots-clés : biodiversité / écologie des rivières / biomonitoring / échantillonnage Hester-Dendy / échantillonnage Hess

\footnotetext{
${ }^{*}$ Corresponding author: tronstad@uwyo.edu
} 


\section{Introduction}

Aquatic invertebrates are excellent indicators of ecosystem health and have been used to monitor stream habitats since the 1870s (Cairns and Pratt, 1993). Their wide use stems from several useful characteristics: aquatic invertebrates are abundant, sedentary, long-lived, responsive to environmental changes, and easy to collect. Most importantly, some aquatic invertebrates are more sensitive to ecosystem changes (e.g., many Ephemeroptera), while others are more tolerant (e.g., many Diptera), making them ideal for monitoring programs. Methods to monitor ecosystems via aquatic invertebrates are well-developed (Johnson et al., 1993; Rosenberg and Resh, 1993) and changes, such as the introduction of invasive species, pollution, alterations in land use and habitat degradation, are reflected in their assemblages.

For researchers and managers, deciding on an aquatic invertebrate sampling method can be difficult. The choice is multi-faceted, and depends upon monitoring objectives, environmental logistics, resource availability, and the presence or absence of historical data associated with a particular method. All methods have advantages and disadvantages, and bioassessment studies use a wide array, including kicknets, fixed-area samplers (e.g., Hess; Waters and Knapp, 1961), artificial substrates (e.g., HD; Hester and Dendy, 1962), and dipnets (Carter and Resh, 2001). Stream characteristics also play a major role in this decision, with plate-style artificial substrate samplers (e.g., HD) that hang freely in the water column best-suited to large, deep rivers where other methods are challenging to use (De Pauw et al., 1986).

Different sampling methods collect different types of data. For example, dipnets and kicknets provide presence/absence data, quantitative samplers [e.g., Hess and Surber (Surber, 1936)] provide estimates of the density and biomass of invertebrates in a given area, while artificial substrate samplers allow for in situ colonization yielding a sampler-based estimate of density. HD samplers are commonly used in the United States, but many iterations of artificial substrate samplers exist, both in terms of colonization medium [e.g., sampling plates or netting (Czerniawska-Kusza, 2004)] and materials (e.g., metal, wood, polyethylene, etc.). This wide variation in artificial substrate sampling methods contributes to the need to interpret results obtained from artificial substrate samplers (e.g., HD) with caution as they may bias samples towards specific taxa (Shaw and Minshall, 1980; Letovsky et al., 2012). Some investigators use multiple methods (e.g., artificial substrate samplers and quantitative methods; Holt et al., 2015) to provide parallel data of the invertebrate assemblage. However, given the challenge of management objectives, using a two- or three-pronged sampling scheme is too expensive in many instances. Therefore, managers are faced with the difficult challenge of making an informed decision about which sampling approach to use.

In this study, we compared HD (artificial Masonite plates) and Hess (fixed-area) sampling methods for characterizing invertebrate assemblages and informing bioassessment trends for the Niobrara River of western Nebraska, USA. Both methods are widely used in stream ecology and more commonly used in the United States versus Europe (at a rate of $\sim 3.5 \times$, Tab. S1). Despite this prevalence, we are not aware of any studies beyond the present one that directly compare the two methods. Specifically, we addressed three questions: (1) How do invertebrate assemblages that colonize HD plates versus those collected via Hess samplers compare? (2) How similar are bioassessment metrics calculated using each sampling method over the same timeframe and when combined with long-term bioassessment data? (3) To what extent has ecosystem health in the Niobrara River changed through time? The study was conducted at Agate Fossil Beds National Monument (AGFO) in western Nebraska where the National Park Service (NPS) has been monitoring aquatic invertebrates at three sites along the Niobrara River using HD sampling since 1996. With the support of the NPS, the present study is a continuation of this long-term sampling. To address our study objectives, we sampled the same sites using both HD and Hess samplers annually over a 5-year period (2010-2014). This allowed us to compare trends in biomonitoring metrics for both sampling methods (HD or Hess) when the recent, comparative data (2010-2014) were added to the long-term HD dataset (1996-2009; Bowles et al., 2013).

\section{Materials and methods}

\subsection{Study area}

The headwaters of the Niobrara River are in eastern Wyoming, and the river flows east into Nebraska, eventually draining into the Missouri River. The Niobrara River Basin covers $32600 \mathrm{~km}^{2}$ of primarily grassland, and over $95 \%$ of the basin is used for agriculture (Galat et al., 2005). AGFO includes $\sim 11 \mathrm{~km}^{2}$ in a valley bottom, and $\sim 18 \mathrm{~km}$ of river flows through the park (Fig. 1). Within the park, riparian vegetation is dominated by cattails (Typha sp.) and invasive yellow flag iris (Iris pseudacorus). River substrate mainly consists of fine particles (e.g., sand, silt and clay). Currently, pike (Esox lucius), white suckers (Catostomus commersonii), and green sunfish (Lepomis cyanellus) are the dominant fish species within the park; however, 11 fish species were collected at AGFO prior to 1990 (Spurgeon et al., 2014).

We sampled three long-term NPS monitoring sites along the Niobrara River each summer (June-August) from 2010 to 2014 (Figs. 1 and S1; Tabs. 1, S2, and S3). We chose the summer season to follow historical sampling practices (19962009). The most upstream site (Agate Springs Ranch) is located near the western park boundary and the substrate is mostly fine sediment. Agate Springs Ranch has an overstorey of plains cottonwood (Populus deltoides) and cattails are more abundant at this site than iris. The central site, Agate Middle, lacks an overstorey, has gravel substrate, and abundant iris and cattails. Agate East is located before the Niobrara River flows out of the park. Riparian vegetation is dominated by iris with a few willow (Salix spp.) and the substrate is primarily fine.

At each site, we measured a range of environmental variables. Air temperature was estimated with a hand-held thermometer. Water temperature, dissolved oxygen concentration and saturation, specific conductivity (SPC), $\mathrm{pH}$ and oxidation-reduction potential (ORP) were measured with a Yellow Springs Instrument Professional Plus Multiprobe calibrated on-site before measurements were collected. Discharge was calculated with a Flo-Mate 2000 by measuring depth and water velocity at $0.3 \mathrm{~m}$ intervals across the stream. 


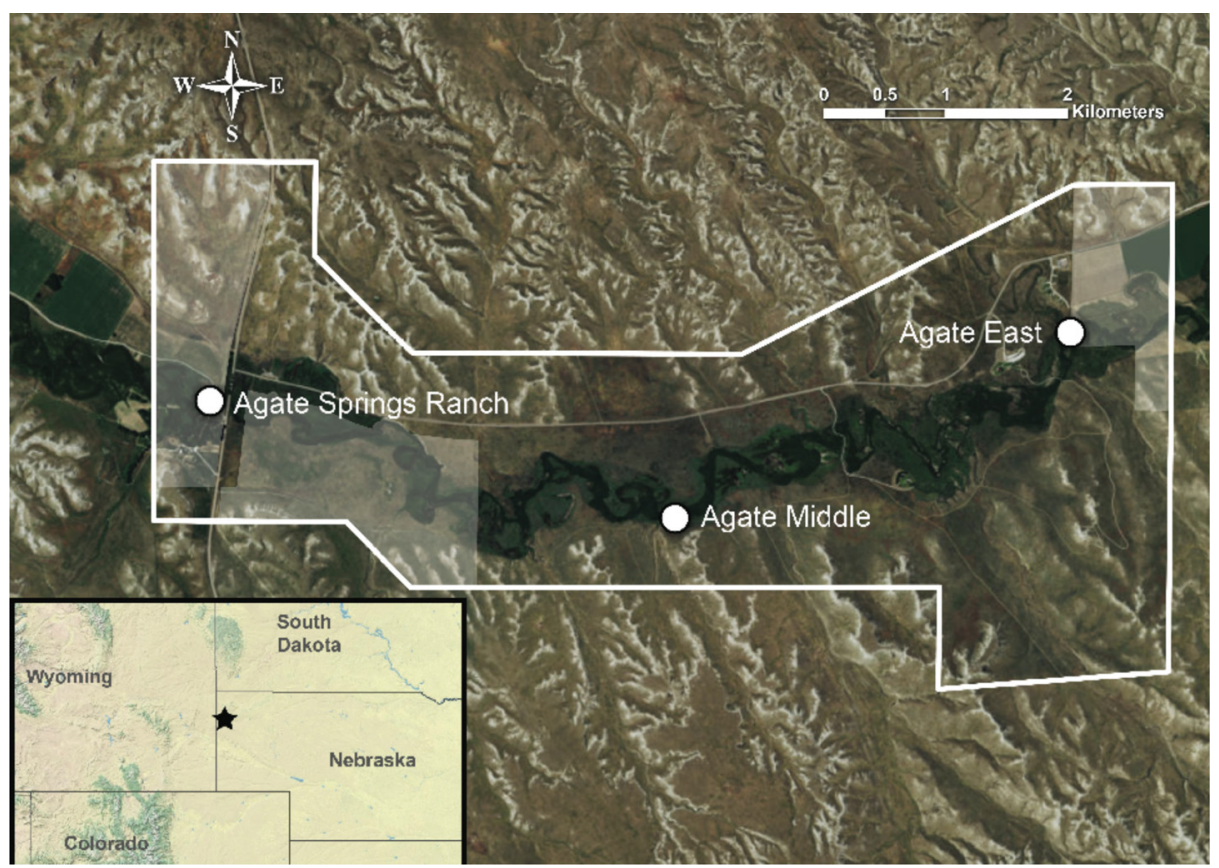

Fig. 1. Sampling sites (white circles) along the Niobrara River at Agate Fossil Beds National Monument (AGFO) in western Nebraska, USA. The white line represents the park boundary and transparent white areas are private land within AGFO. The inset map shows the location of AGFO in Nebraska (star).

Table 1. Environmental variables measured across study years (2010-2014) for each site along the Niobrara River. Site abbreviations include: East $=$ Agate East, Middle $=$ Agate Middle, and Ranch $=$ Agate Springs Ranch . Variable abbreviations include: $T_{\mathrm{w}}=$ water temperature $\left({ }^{\circ} \mathrm{C}\right)$, $T_{\text {air }}=$ air temperature $\left({ }^{\circ} \mathrm{C}\right), \mathrm{DO}=$ dissolved oxygen $(\mathrm{mg} / \mathrm{L}), \mathrm{SPC}=$ specific conductivity $(\mu \mathrm{S} / \mathrm{cm}), \mathrm{ORP}=$ oxidation-reduction potential $(\mathrm{mV})$, $D=$ depth $(\mathrm{cm}), W=$ total wetted width $(\mathrm{m})$ including the floodplain, and Dis. $=$ discharge $\left(\mathrm{m}^{3} / \mathrm{s}\right)$. Variables are averaged between the initial and final visits.

\begin{tabular}{|c|c|c|c|c|c|c|c|c|c|c|c|c|}
\hline Site & Year & $T_{\mathrm{w}}$ & $T_{\text {air }}$ & $\% \mathrm{DO}$ & DO & SPC & $\mathrm{pH}$ & ORP & Secchi & $D$ & $W$ & Dis. \\
\hline East & 2010 & 18.0 & 28 & 69 & 5.6 & 442.1 & 7.8 & 163.7 & 97.0 & 92.4 & 2.7 & - \\
\hline East & 2011 & 19.6 & 26 & 98 & 7.7 & 417.0 & 7.9 & 47.8 & 25.5 & 65.3 & - & - \\
\hline East & 2012 & 26.0 & 37 & 102 & 8.0 & 304.0 & 8.0 & 200.0 & 45.0 & 58.1 & 2.2 & 0.21 \\
\hline East & 2013 & 20.0 & 21 & 69 & 6.0 & 392.0 & 8.0 & 167.0 & 73.0 & 41.8 & 3.4 & 0.11 \\
\hline East & 2014 & 21.0 & 33 & 76 & 7.0 & 351.0 & 7.0 & 193.0 & 77.0 & 50.8 & 2.3 & 0.11 \\
\hline Middle & 2010 & 19.5 & 19 & 80 & 6.3 & 437.5 & 7.8 & 108.3 & 60.0 & 54.4 & 3.0 & - \\
\hline Middle & 2011 & 20.7 & 34 & 116 & 8.9 & 418.6 & 7.9 & 48.3 & 39.0 & 45.7 & - & - \\
\hline Middle & 2012 & 23.9 & 35 & 113 & 9.7 & 307.7 & 8.1 & 196.9 & 27.5 & 35.3 & 2.2 & 0.11 \\
\hline Middle & 2013 & 22.1 & 26 & 71 & 6.4 & 384.5 & 7.5 & 163.1 & 68.0 & 46.5 & 6.8 & 0.07 \\
\hline Middle & 2014 & 21.3 & 28 & 53 & 4.7 & 343.4 & 7.4 & 78.1 & 70.5 & 67.7 & 4.2 & 0.08 \\
\hline Ranch & 2010 & 20.2 & 27.5 & 94 & 7.2 & 418.3 & 8.2 & 185.4 & 64.0 & 59.3 & 2.2 & - \\
\hline Ranch & 2011 & 21.0 & 34 & 116 & 8.8 & 414.1 & 8.1 & 90.7 & 40.0 & 55.3 & - & - \\
\hline Ranch & 2012 & 20.7 & 35 & 97 & 8.8 & 318.6 & 8.2 & 199.6 & 52.0 & 47.1 & 2.7 & 0.17 \\
\hline Ranch & 2013 & 19.5 & 24 & 99.5 & 9.3 & 394.7 & 8.1 & 193.3 & 48.9 & 48.2 & 3.1 & 0.16 \\
\hline Ranch & 2014 & 21.2 & 25.5 & 70 & 6.2 & 348.3 & 7.8 & 71.7 & 69.5 & 53.1 & 2.7 & 0.17 \\
\hline
\end{tabular}

We measured water clarity by lowering a Secchi disk into the water until it disappeared from view. Dominant substrate was estimated through soil texture tests (Thien, 1979). For all environmental variables, measurements were taken during mid-day hours to minimize among-site variation to the greatest degree possible.

\subsection{Field sampling and laboratory methods}

We deployed HD samplers $(76 \times 76 \mathrm{~mm}, 9$ square plates, Wildlife Supply Company) at each study site in either June or July for all years. Specifically, a rope was strung across the river between two posts and seven loops were tied to separate the HD 
Table 2. Unique invertebrate taxa found only in Hess or Hester-Dendy samples. Insect orders are bolded and most unique taxa are identified to genus.

\begin{tabular}{lll}
\hline Hess & & \\
Coleoptera & Lampyridae & Pericoma/Telmatoscopus \\
Berosus & Neoporus & Probezzia \\
Coptotomus & Staphylinidae & Sciomyzidae \\
Curculionidae & & Stratiomys \\
Enochrus & Diptera & Syrphidae \\
Helophorus & Chrysops & Tipula \\
Hydrophilus & Dicranota & \\
Hydroporus & Dixa & Hemiptera \\
Hygrotus & Helius & Limnoporus \\
Ilybius & Hybomitra & Palmacorixa \\
Laccobius & Mallochohelea & Trepobates \\
& & \\
Hester-Dendy & & \\
Coleoptera & & \\
Dineutus & Ephemeroptera & \\
Dytiscus & Ephemerillidae & \\
Sanfilippodytes & & \\
\hline
\end{tabular}

plates (Fig. S2a-c). The bottom of each plate was $\geq 15 \mathrm{~cm}$ above the stream bottom. Similar to previous studies (e.g., Wilson et al., 2004), plates were colonized for $\sim 30$ days (Tab. S3). Debris that accumulated was cleared weekly. Plates were retrieved by approaching from downstream and placing a dip net $(150 \mu \mathrm{m}$ mesh) under each HD and cutting the attached rope. Both HD plates and any invertebrates in the dipnet were included in the sample. HD plates were scrubbed with a toothbrush to remove invertebrates and samples were rinsed in a $212 \mu \mathrm{m}$ sieve. Only five of the seven plates were analyzed from each site. Typically, the middle five plates were used unless one sampler was compromised (e.g., touching the bottom, pushed out of the water, etc.). All specimens were preserved in $80 \%$ ethanol.

When HD samples were retrieved (either in July or August), we collected five replicate Hess samples $(500 \mu \mathrm{m}$ mesh, $860 \mathrm{~cm}^{2}$ sampling area, Wildlife Supply Company) from each site (Fig. S2d and e; except in 2010 we only collected three). The exception to this sampling scheme was a drought year (2012) when Hess samples were collected during HD deployment to avoid low water levels. At each site, Hess samplers were placed over vegetation at the margin of the stream, and both vegetation and sediment were vigorously scoured to capture invertebrates. All specimens were preserved in $80 \%$ ethanol.

In the laboratory, invertebrates were sorted and identified using a dissecting microscope. Each sample was filtered through a $2 \mathrm{~mm}$ mesh sieve and a 212 or $500 \mu \mathrm{m}$ sieve to separate larger, less abundant invertebrates from smaller, more abundant taxa. All invertebrates were identified in the $>2 \mathrm{~mm}$ size class. If the density of invertebrates in the small sieve was high, we subsampled using the record player method (Waters, 1969). Identifications were made using Merritt et al. (2008) for insects, and Thorp and Covich (2009) and Smith (2001) for non-insect invertebrates. Insects were identified to genus when mature larvae were collected and non-insects were identified to the lowest practical taxonomic level (see Tabs. S5 and S6). Finally, replicate samples were averaged to calculate final values used in downstream comparisons and analyses.

\subsection{Statistical analyses}

Six bioassessment metrics have been calculated for the Niobrara River to estimate ecosystem health since 1996: Hilsenhoff's biotic index (HBI), Ephemeroptera, Plecoptera and Trichoptera (EPT) richness, proportion of EPT taxa (i.e., number of EPT taxa divided by total number of taxa collected), taxon diversity (Shannon's index), taxon richness and taxon evenness (Bowles et al., 2013). We followed historical methods and calculated these same metrics as well as the proportion of invertebrate groups (e.g., insects, Ephemeroptera, Crustacea) for both sampling methods and analyzed differences using analysis of variance (ANOVA) models with site, year, and sampling method as variables after testing model assumptions. We used the false discovery rate (Benjamini and Hochberg, 1995) to correct $P$-values, because we ran 17 ANOVAs on subsets of our dataset. We ordered groups by $P$-values from smallest to largest (i.e., the group with the smallest $P$-value was first and the group with the largest $P$ value was $17 \mathrm{th})$. We calculated the adjusted alpha level by dividing 0.05 by the number of tests (17) and multiplying by the consecutive order of the group. The group was significant when the $P$-value was smaller than the adjusted alpha level. All groups with smaller $P$-values were significant above the group with the largest, significant $P$-value. To organize, split, and manage data sets, we used the $\mathrm{R}$ packages plyr (Wickham, 2011) and Matrix (Bates and Maechler, 2010).

We used non-metric multidimensional scaling (NMDS) ordinations ( $\mathrm{R}$ package vegan; Oksanen et al., 2007) to visualize variation in aquatic invertebrate assemblages between sampling methods over the 5-year study interval (2010-2014). NMDS provides an ordination-based approach to rank distances between objects and has been shown to perform well with non-normally distributed data (Legendre and Legendre, 1998). We performed NMDS on the mean abundance of taxa per sample with replicates combined for each site, year, and sampler type. NMDS iterations were run 
L.M. Tronstad and S. Hotaling: Knowl. Manag. Aquat. Ecosyst. 2017, 418, 28
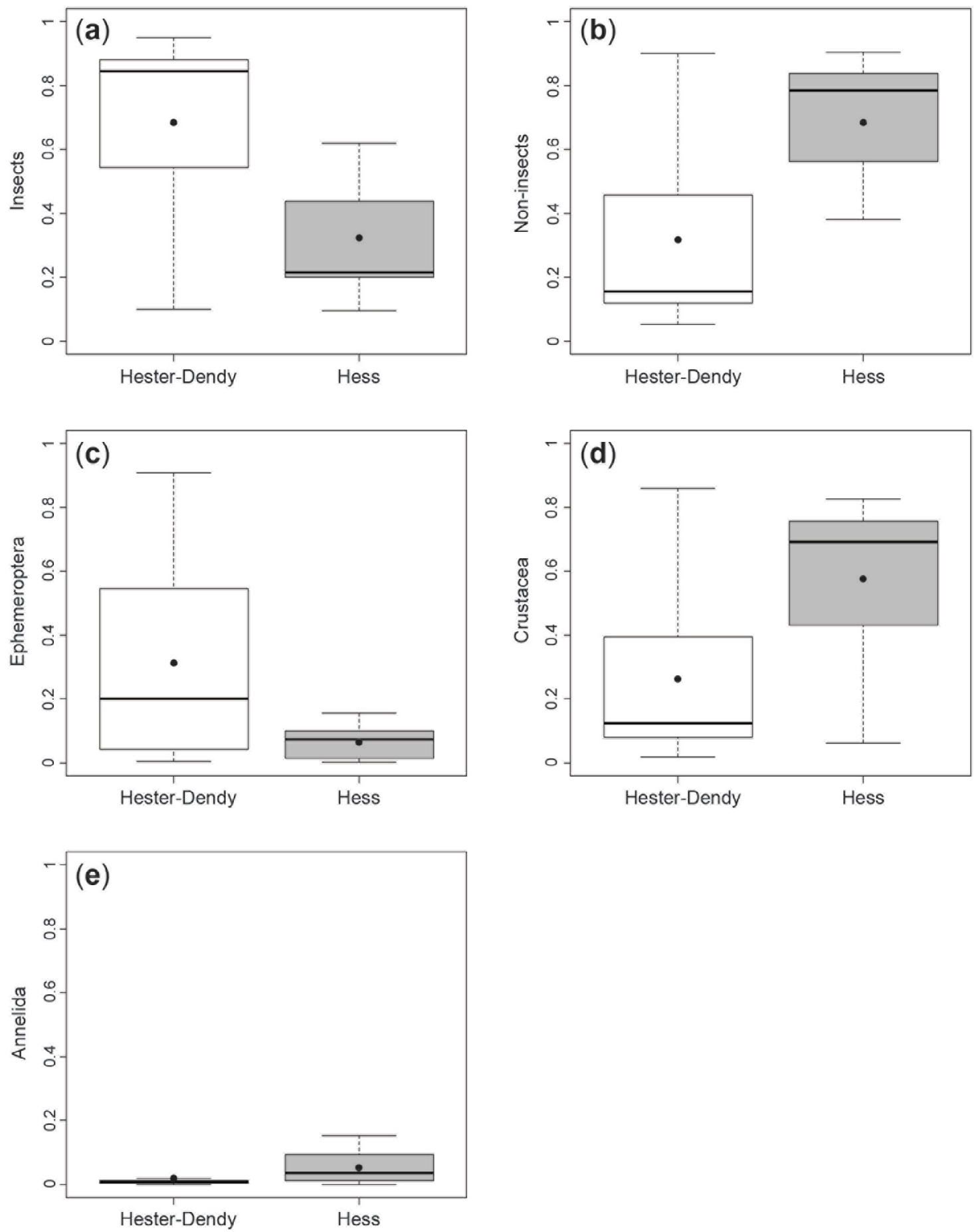

Fig. 2. Proportions of (a) insects, (b) non-insects, (c) Ephemeroptera, (d) Crustacea, and (e) Annelida that significantly differed between HesterDendy and Hess samples. Black circles represent mean values and bold lines are median values, lower and upper box limits are the 25 th and 75 th percentiles and whiskers indicate the upper and lower limits of the data.

until convergence on a locally minimum stress was achieved. A 2D solution was used to simplify interpretation. Next, a goodness-of-fit of the NMDS results was assessed through a regression of the observed Bray-Curtis dissimilarities and NMDS ordination distances. We calculated multivariate dispersion for each sampling method to understand the inherent variability of HD versus Hess samples. To test significance of dispersion between methods, we used a permutation test of multivariate homogeneity of group dispersions. This test first employ a $t$-test to assess pairwise group dispersions, followed by a permutation test to generate a distribution of $F$ under a null hypothesis of no dispersion (or variance) between groups. All multivariate analyses were performed using the $\mathrm{R}$ package vegan 
L.M. Tronstad and S. Hotaling: Knowl. Manag. Aquat. Ecosyst. 2017, 418, 28
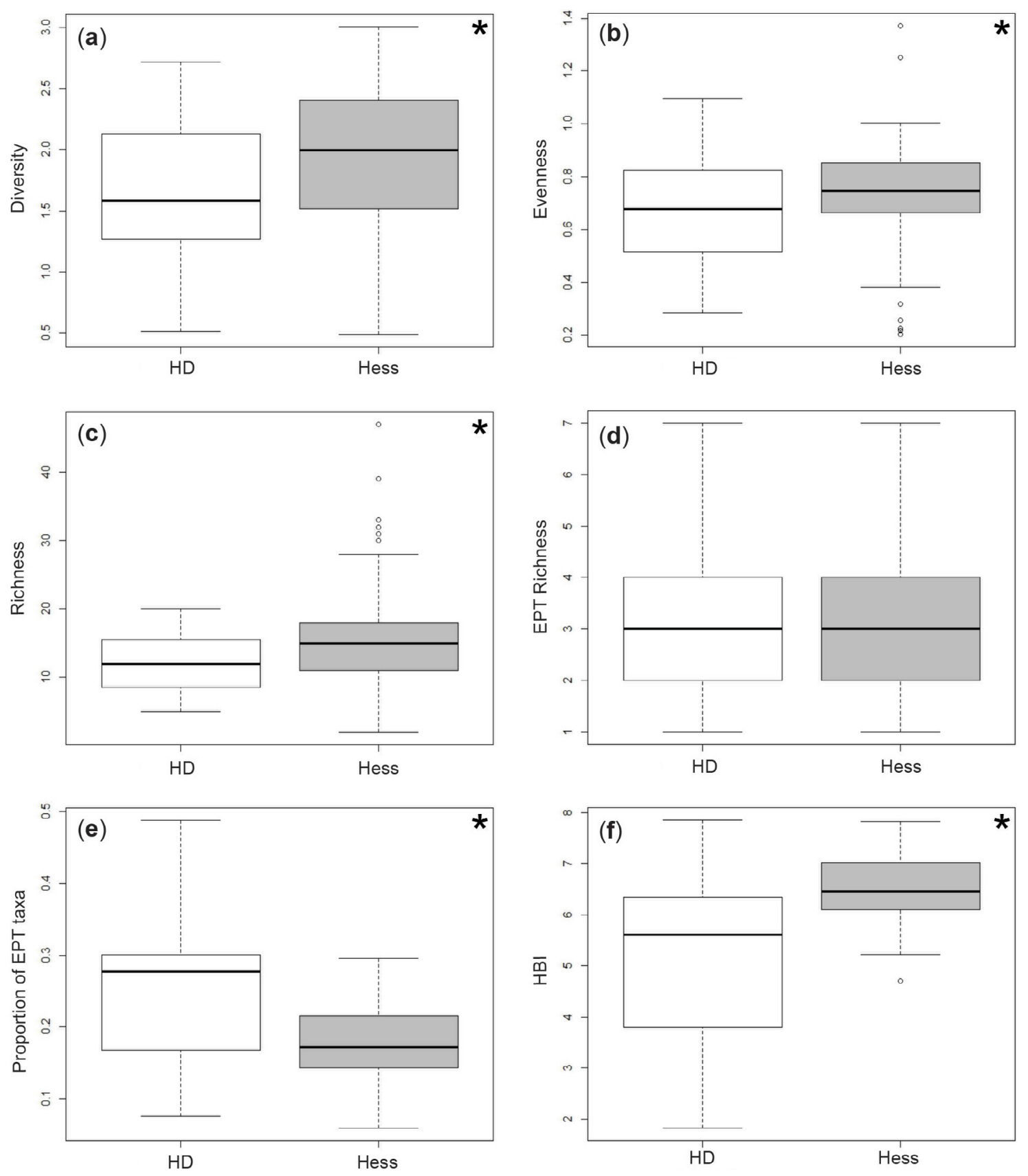

Fig. 3. (a) Diversity, (b) evenness, (c) richness, (d) Ephemeroptera, Plecoptera and Trichoptera (EPT) richness, (e) proportion of EPT taxa, and (f) Hilsenhoff's biotic index (HBI) calculated from Hester-Dendy and Hess samples collected annually from 2010 to 2014 in the Niobrara River. Higher values of all metrics except HBI indicate better ecosystem health. The bold line is the median, lower and upper box limits are the 25 th and 75th percentiles, and whiskers represent the upper and lower limits of the data with circles indicating outliers. Asterisks indicate comparisons that are significant.

(Oksanen et al., 2007) with default settings. Because input data for NMDS must have the same units, we used principal components analysis (PCA) to assess environmental variation and bioassessment metrics between sampling methods and study sites. PCAs were performed in $\mathrm{R}$ using the standard package prclust.

To analyze long-term trends in bioassessment metrics and assess the degree to which ecosystem health in the Niobrara River has changed over time, we used functional data analysis
(FDA; Ramsay 2006). FDA is particularly useful in this context as it provides a means to capture non-linear trends (e.g., in bioassessment metrics) and compare them among study sites (Henderson, 2006). Bioassessment metrics were plotted against time with slopes and standard errors (SEs) calculated for each site to analyze the data using FDA. Ninetyfive percent confidence intervals (CIs) were estimated based on $\mathrm{SE}$ for each metric with trends considered significant when the CI did not include zero. 
Table 3. Mean invertebrate bioassessment metrics and standard errors calculated from Hester-Dendy and Hess samplers during the 5-year comparative study period (2010-2014). Five samples for each method were collected during all years with the exception of 2010 when three Hess samples were collected. HBI $=$ Hilsenhoff's biotic index.

\begin{tabular}{|c|c|c|c|c|c|c|}
\hline Metric & 2010 & 2011 & 2012 & 2013 & 2014 & Mean \\
\hline \multicolumn{7}{|l|}{ Hester-Dendy } \\
\hline Taxon diversity & $1.37 \pm 0.12$ & $1.25 \pm 0.25$ & $1.31 \pm 0.10$ & $2.11 \pm 0.17$ & $2.16 \pm 0.11$ & $1.64 \pm 0.06$ \\
\hline Taxon evenness & $0.51 \pm 0.02$ & $0.59 \pm 0.06$ & $0.63 \pm 0.03$ & $0.08 \pm 0.04$ & $0.82 \pm 0.02$ & $0.67 \pm 0.02$ \\
\hline Proportion EPT & $0.24 \pm 0.02$ & $0.31 \pm 0.04$ & $0.32 \pm 0.04$ & $0.20 \pm 0.03$ & $0.23 \pm 0.03$ & $0.26 \pm 0.01$ \\
\hline Taxon richness & $15.1 \pm 0.81$ & $8.4 \pm 0.55$ & $8.3 \pm 0.58$ & $15.0 \pm 0.70$ & $14.3 \pm 0.59$ & $12.2 \pm 0.47$ \\
\hline EPT richness & $3.5 \pm 0.24$ & $2.5 \pm 0.36$ & $2.8 \pm 0.42$ & $2.9 \pm 0.37$ & $3.4 \pm 0.47$ & $3.07 \pm 0.17$ \\
\hline HBI & $5.49 \pm 0.50$ & $5.04 \pm 0.58$ & $3.88 \pm 0.29$ & $5.66 \pm 0.15$ & $5.82 \pm 0.14$ & $5.18 \pm 0.18$ \\
\hline \multicolumn{7}{|l|}{ Hess } \\
\hline Taxon diversity & $1.08 \pm 0.21$ & $1.58 \pm 0.11$ & $2.22 \pm 0.12$ & $2.25 \pm 0.13$ & $2.15 \pm 0.35$ & $1.92 \pm 0.07$ \\
\hline Taxon evenness & $0.43 \pm 0.06$ & $0.81 \pm 0.06$ & $0.85 \pm 0.03$ & $0.80 \pm 0.02$ & $0.66 \pm 0.05$ & $0.73 \pm 0.03$ \\
\hline Proportion EPT & $0.20 \pm 0.00$ & $0.23 \pm 0.02$ & $0.21 \pm 0.02$ & $0.11 \pm 0.01$ & $0.14 \pm 0.01$ & $0.18 \pm 0.01$ \\
\hline Taxon richness & $14.2 \pm 1.63$ & $9.0 \pm 0.99$ & $14.1 \pm 0.74$ & $17.3 \pm 1.12$ & $25.2 \pm 2.74$ & $16.1 \pm 0.94$ \\
\hline EPT richness & $2.7 \pm 0.32$ & $2.3 \pm 0.31$ & $3.1 \pm 0.34$ & $1.9 \pm 0.25$ & $3.7 \pm 0.52$ & $3.1 \pm 0.17$ \\
\hline $\mathrm{HBI}$ & $7.22 \pm 0.32$ & $6.91 \pm 0.08$ & $6.51 \pm 0.18$ & $5.97 \pm 0.10$ & $6.18 \pm 0.09$ & $6.50 \pm 0.08$ \\
\hline
\end{tabular}

\section{Results}

We collected 55 invertebrate taxa using HD samplers and 84 taxa using Hess sampling. When both methods were combined, we identified a total of 88 taxa from five phyla (Annelida, Mollusca, Nematoda, Nemertea and Arthropoda) in the Niobrara River. Four taxa were only observed in HD samples and 33 taxa were unique to Hess samples (Tab. 2). Unique taxa observed in HD samples were Coleoptera and early instar Ephemerellidae, with both found at low densities $\left(\leq 20 \mathrm{ind} . / \mathrm{m}^{2}\right)$. In contrast, we collected unique taxa of Coleoptera, Diptera, Hemiptera, Megaloptera, Odonata and Trichoptera in Hess samples $(\leq 60$ ind. $/ \mathrm{m}^{2}$; Tabs. S5 and S6). Overall, Diptera, Crustacea and Ephemeroptera were the most numerous invertebrates in HD samples whereas Crustacea, Diptera and Mollusca were the most numerous in Hess samples.

We did not detect a difference in the number of invertebrates collected in HD samples (mean $=337$ ind./ sample) compared to Hess samples (mean $=408$ ind./sample; ANOVA $P=0.22$ ); however, the proportion of taxa often differed. The proportion of insects was twice as high in HD samples compared to Hess samples (Fig. 2a; $P \leq 0.001$ ); however, the proportion of non-insect invertebrates in Hess samples was two times higher than in HD samples (Fig. 2b; ANOVA $P<0.001)$. The proportion of Ephemeroptera in Hester-Dendy (HD) samples was nearly five times higher than in Hess samples (Fig. 2c; $P \leq 0.001$ ). Conversely, the proportion of crustaceans in Hess samples was more than two times greater than in HD samples (Fig. $2 \mathrm{~d} ; P<0.001$ ) and the proportion of annelids was nearly three times higher in Hess versus HD samples (Fig. 2e; $P=0.029$ ). We did not detect differences in the proportion of taxon between Hess and HD samples for Mollusca $(P=0.18)$, Diptera $(P=0.11)$, Hemiptera $(P=0.08)$, Coleoptera $(P=0.39)$, Odonata $(P=0.15)$, and Trichoptera $(P=0.25)$. Taxon diversity (Fig. 3a; $P$ $<0.001$ ), taxon evenness (Fig. 3b; $P=0.029$ ), taxon richness
(Fig. 3c; $P<0.001$ ) and HBI (Fig. 3f; $P<0.001$ ) were higher in Hess samples and the proportion of EPT taxa (Fig. 3e; $P=0.008$ ) was higher in HD samples (Figs. 3 and S3; Tab. 3). Conversely, EPT richness (Fig. $3 \mathrm{~d} ; P=0.93$ ) was similar between methods (Fig. 3d). Statistical results for all ANOVA comparisons are include in Table S4.

NMDS analyses revealed that HD and Hess samples captured similar invertebrate assemblages; however, HD yielded a broader assemblage profile than Hess samples (Fig. 4a). Analysis of multivariate dispersion showed greater variation between replicate HD versus Hess samples $(P$ $<0.01$; Fig. $4 \mathrm{~b}$ and c). Sampling year affected the invertebrate assemblage collected (Fig. S4a) while sampling site had no discernible influence (Fig. 4d). Sampling year had a greater influence on environmental variation among sites than specific locations. This environmental variation among sites was largely driven by SPC, ORP, water clarity, and discharge (Fig. $4 \mathrm{e})$. When bioassessment metrics were compared, the two methods formed distinct clusters in PC space with seemingly little influence of specific sampling years (Fig. 4f). Moreover, taxa richness, EPT richness, and HBI were the most influential bioassessment metrics in separating results calculated for each sampling method (Fig. 4f).

Despite many differences between sampling methods, there was no significant influence of substituting HD or Hess data from 2010 to 2014 into long-term bioassessment calculations (Fig. 5). Regardless of which recent data set was included, long-term trends in bioassessment metrics clearly showed declining health in the Niobrara River ecosystem over the last 19 years (Tab. 4). Aside from biased representations of invertebrate assemblages that stemmed from HD sampling, Hess samples also required similar or fewer net resources per sample in our study. HD samples required weekly trips to clear debris (five trips) versus only one trip for Hess samples (Tab. 5). Therefore, the value of Hess sampling increases with distance to and from study sites. 

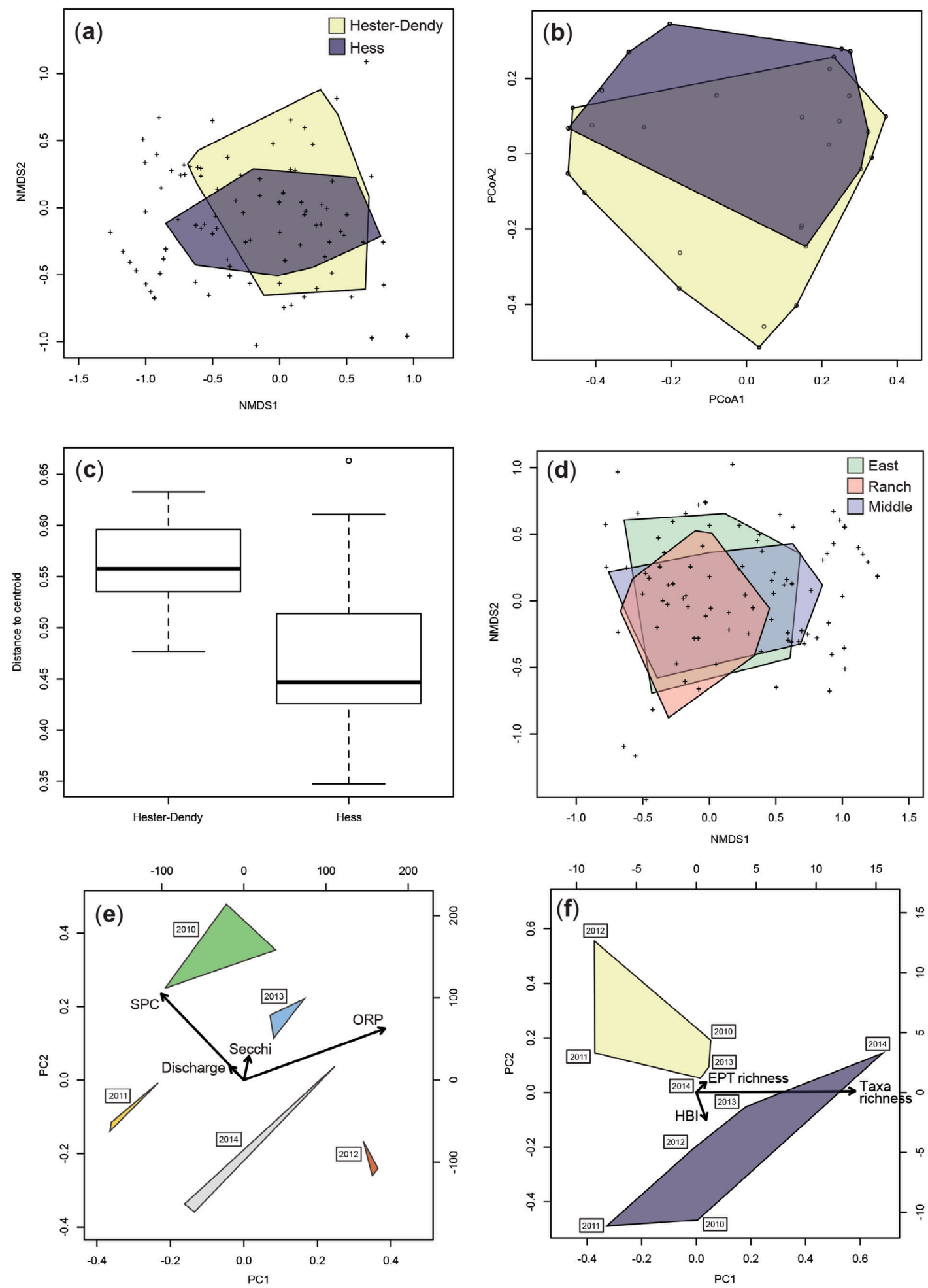

Fig. 4. Comparisons of Hester-Dendy and Hess sampling methods and environmental variation across study sites from 2010 to 2014 using nonmetric multidimensional scaling (NMDS), multivariate dispersion, and principal component analysis (PCA) for the Niobrara River. (a) NMDS comparison of invertebrate assemblages, (b) multivariate dispersion of invertebrate assemblages, (c) distance-to-center of boxplots for the multivariate dispersion polygons shown in (b), (d) NMDS comparison of invertebrate assemblages across sites for both methods, (e) PCA comparison of environmental variation among sites, and (f) PCA comparisons of six bioassessment metrics for methods and years, Hash marks represent: (a) individual taxa and (b) sampling events for all years and methods. For (e) and (f), polygon corners represent sampling sites (e) or years (f) and only variables with non-negligible influence are shown though the full suite of relevant metrics were included for each PCA. Abbreviations: $\mathrm{ORP}=$ oxidative reduction potential, $\mathrm{SPC}=$ specific conductivity. 

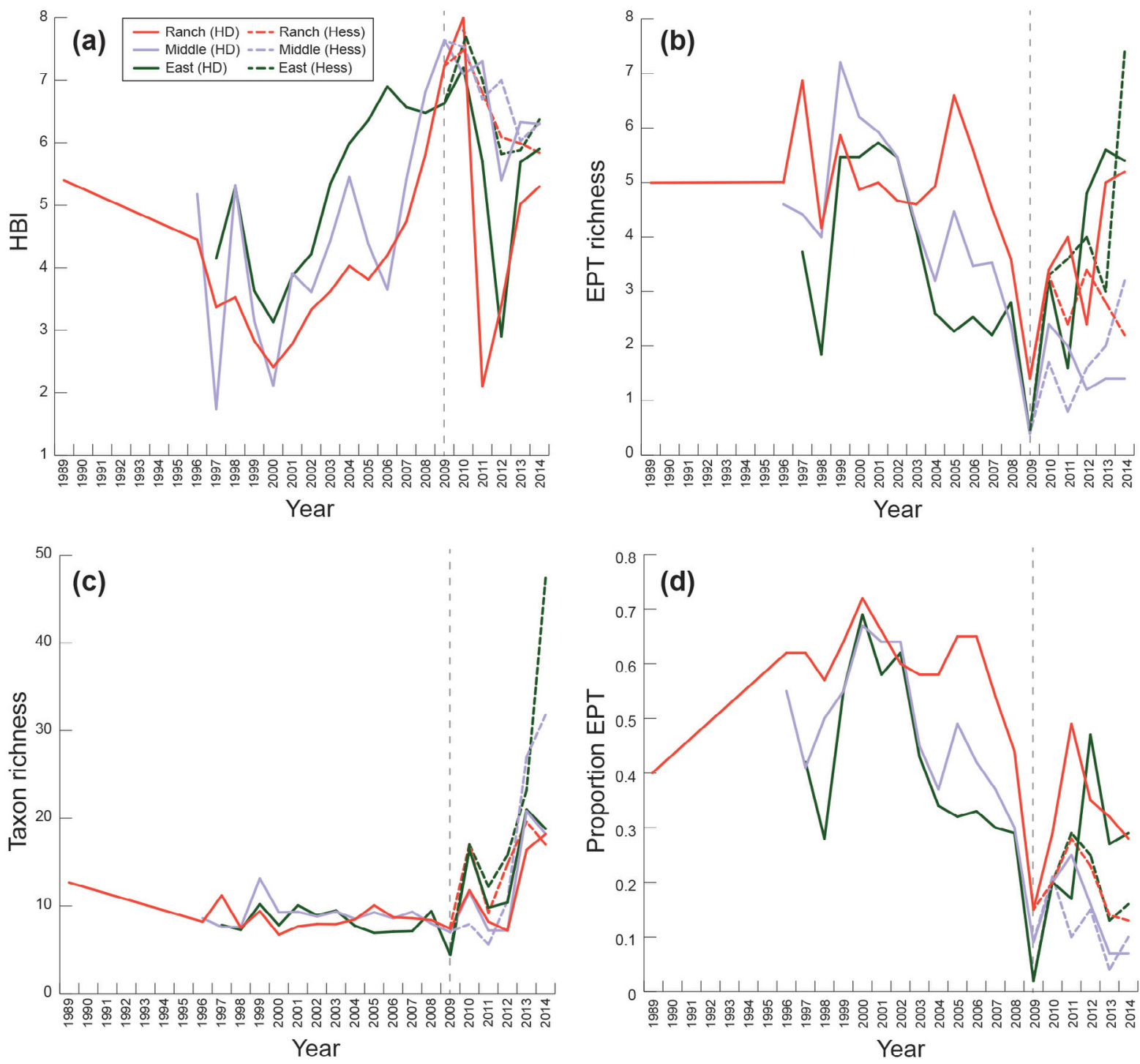

Fig. 5. Invertebrate bioassessment metrics over time from the Niobrara River at Agate Fossil Beds National Monument, Nebraska, USA. (a) Hilsenhoff's biotic index (HBI), (b) Ephemeroptera, Plecoptera and Trichoptera (EPT) richness, (c) taxon richness, and (d) proportion of EPT taxa. Vertical dashed lines indicate where past data (1989-2009) from Bowles et al. (2013) end and newly collected data for both HD (solid) and Hess (dashed) lines begin.

\section{Discussion}

\subsection{HD versus Hess sampling}

Our results support broader themes in aquatic ecology that invertebrate assemblages collected with artificial substrate samplers (e.g., HD) differ from those collected with other techniques. Specifically, HD samplers tend to collect lower taxon diversity versus other methods (Shaw and Minshall, 1980; Blocksom and Flotemersch, 2005; Letovsky et al., 2012; McCabe et al., 2012; Macanowicz et al., 2013), a result we also observed for the Niobrara River when comparing HD and Hess sampling. The limited diversity observed using HD samplers may be because some invertebrates are limited in their ability to colonize HD plates due to habitat requirements (e.g., no sediment to burrow into), functional feeding group (e.g., a shredder with no access to leaves), or other factors. In the Niobrara River, Hess samples consistently recovered higher taxon diversity, a larger proportion of non-insect invertebrates, crustaceans and annelids, and a smaller proportion of insects and mayflies. These differences extended to bioassessment metrics in our comparative data set (2010-2014) with taxon richness differing most dramatically between HD and Hess sampling. Bioassessment metrics were elevated in HD samples due to a higher density of mayflies (an EPT component) colonizing the plates, a pattern previously observed (Canton and Chadwick, 1983; Letovsky et al., 2012). Furthermore, individual HD samples were more taxonomically variable, likely a product of a wider array of colonization conditions (e.g., the amount of debris or algae accumulating while the HD plates were colonizing). An alternate explanation could be differences in the way HD samples were handled and processed, but because identical field and laboratory methods (including the same personnel) were used, it is unlikely that differences were handling related. 
Table 4. Functional data analysis of bioassessment metrics through time. Hester-Dendy samples were collected at all sites from 1997 to 2014. Hess samples were also collected from 2010 to 2014 and analyzed with Hester-Dendy data from 1997 to 2009. Slope, standard error (SE), and a $95 \%$ confidence interval (CI) are reported for each metric and site. Year was the independent variable in all analyses. The relationship was significant (bold) when the CI did not include zero. Abbreviations: Ranch = Agate Springs Ranch, Middle = Agate Middle, East= Agate East, and $\mathrm{HBI}=$ Hilsenhoff's biotic index.

\begin{tabular}{|c|c|c|c|c|c|c|}
\hline & \multicolumn{3}{|c|}{ Hester-Dendy } & \multicolumn{3}{|c|}{ Hess } \\
\hline & Slope & SE & $\mathrm{CI}$ & Slope & SE & CI \\
\hline \multicolumn{7}{|l|}{$H B I$} \\
\hline Ranch & 0.066 & 0.053 & & 0.158 & 0.045 & \\
\hline Middle & 0.214 & 0.052 & & 0.209 & 0.052 & \\
\hline East & 0.113 & 0.057 & & 0.184 & 0.042 & \\
\hline Mean & 0.131 & 0.054 & 0.023 to 0.238 & 0.182 & 0.046 & 0.091 to 0.276 \\
\hline \multicolumn{7}{|c|}{ Diversity } \\
\hline Ranch & 0.017 & 0.013 & & 0.009 & 0.009 & \\
\hline Middle & 0.018 & 0.011 & & 0.044 & 0.013 & \\
\hline East & 0.006 & 0.010 & & 0.023 & 0.018 & \\
\hline Mean & 0.014 & 0.012 & -0.009 to 0.037 & 0.025 & 0.013 & -0.001 to 0.052 \\
\hline \multicolumn{7}{|c|}{ Richness } \\
\hline Ranch & 0.125 & 0.106 & & 0.264 & 0.120 & \\
\hline Middle & 0.269 & 0.145 & & 0.565 & 0.256 & \\
\hline East & 0.454 & 0.169 & & 1.095 & 0.372 & \\
\hline Mean & 0.283 & 0.140 & 0.003 to 0.563 & 0.641 & 0.249 & 0.142 to 1.140 \\
\hline \multicolumn{7}{|c|}{ Evenness } \\
\hline Ranch & 0.006 & 0.004 & & 0.000 & 0.004 & \\
\hline Middle & 0.005 & 0.005 & & 0.014 & 0.004 & \\
\hline East & 0.001 & 0.003 & & 0.000 & 0.005 & \\
\hline Mean & 0.004 & 0.004 & -0.004 to 0.012 & 0.005 & 0.004 & -0.004 to 0.013 \\
\hline \multicolumn{7}{|l|}{$E P T$} \\
\hline Ranch & -0.084 & 0.042 & & -0.147 & 0.039 & \\
\hline Middle & -0.272 & 0.046 & & -0.249 & 0.052 & \\
\hline East & -0.034 & 0.078 & & -0.034 & 0.078 & \\
\hline Mean & -0.130 & 0.055 & -0.241 to -0.019 & -0.143 & 0.056 & -0.255 to -0.027 \\
\hline \multicolumn{7}{|c|}{ Proportion EPT } \\
\hline Ranch & -0.013 & 0.005 & & -0.021 & 0.006 & \\
\hline Middle & -0.296 & 0.004 & & -0.031 & 0.005 & \\
\hline East & -0.018 & 0.007 & & -0.024 & 0.006 & \\
\hline Mean & -0.109 & 0.005 & -0.120 to -0.099 & -0.025 & 0.005 & -0.036 to -0.015 \\
\hline
\end{tabular}

Sampling location within the stream, whether the main channel (HD) or margins (Hess), is a factor to consider when deciding on sampling methods. Sampling the main channel with HD plates collected the same taxa that were collected with a Hess sampler in the stream margins. However, sampling with only HD plates would miss many taxa and thereby reduce accuracy as many taxa were only observed via Hess sampling in the stream margins. While a portion of these differences may be due to sampling method, environmental factors likely also play a role. The stream margin is a transitional habitat where the floodplain and stream channel meet. In the Niobrara River, macrophytes are abundant along the stream margin and few aquatic plants grow in the main channel. Macrophytes along the stream margins provide stable substrate for invertebrates to feed upon and use for shelter, whereas the main channel likely offers few natural refugia for invertebrates. Moreover, water velocity is slower and more detritus accumulates in stream margins compared to the main channel. Few benthic invertebrates live in the main channel of the Niobrara River (Tronstad, 2012) and the HD samplers offer substrate that is naturally lacking in the middle of the stream. For managers, we recommend sampling different habitats initially to assess the invertebrate assemblages of each to estimate how representative they may be of the broader community. This preliminary sampling can then be used to identify the best habitat to sample for long-term monitoring. For the Niobrara River specifically, our results indicated that fewer taxa would be overlooked when Hess samples were collected along stream margins compared to both HD sampling and sediment core samples from the main channel (Tronstad, 2012). 
Table 5. Estimates of time to sample, process, and analyze HesterDendy (HD) versus Hess samples. Estimates are based on a 1 month colonization period for HD samples. Travel time was not accounted for which increases HD sampling time as more trips to each site are required for that method. 1 day $=8 \mathrm{~h}$.

\begin{tabular}{lll}
\hline Task & Hester-Dendy & Hess \\
\hline Deploying & 1 day & N/A \\
Clearing debris & 3 days & N/A \\
Collecting & 1 day & 1 day \\
Processing & $\sim 2.5$ h per sample & $\sim 4 \mathrm{~h}$ per sample \\
Identification & $\sim 2 \mathrm{~h}$ per sample & $\sim 3 \mathrm{~h}$ per sample \\
Total time (15 samples) & 13.5 days & 14.1 days \\
\hline
\end{tabular}

\subsection{Long-term changes to the Niobrara River ecosystem}

Relatively few long-term aquatic invertebrate monitoring data sets exist, and the few that do are vital to our collective understanding of how ecosystems change over time, particularly in response to specific events (Jackson and Füreder, 2006; Jackson et al., 2009; Mazor et al., 2009). In this study, four of six bioassessment metrics (HBI, EPT richness, taxa richness and the proportion of EPT taxa) showed significant trends over the 19year monitoring period, regardless of which data set (HD or Hess) was included for the 2010-2014 timeframe. These metrics collectively pointed to a decline in ecosystem health in the Niobrara River. The fact that the overall trend was consistent, regardless of which data set was included suggests that, at least for the Niobrara River, changing methods from HD to Hess may not affect the interpretation of long-term trends.

Despite using the same methods to collect and analyze HD samples, we did observe trends in bioassessment metrics over time that indicated reduced overall ecosystem health. There are two likely explanations for this decline in Niobrara River ecosystem health: the introductions of invasive northern pike (E. lucius) and yellow flag iris (Bowles et al., 2013; Spurgeon et al., 2014). Pike are piscivores and likely caused a decline in the resident fish assemblage from 11 to 3 species between 1989 and 2011 (Spurgeon et al., 2014) triggering a trophic cascade that affected the invertebrate assemblage in the river (Carpenter et al., 1987; Tronstad et al., 2010; Shelton et al., 2015; Wilmot et al., 2016). Furthermore, the invasion of non-native plants may have altered the stream ecosystem (Bowles et al., 2013; Spurgeon et al., 2014). Vegetation surveys revealed that non-native plants composed $32-42 \%$ of the total plant assemblage at each of the sites (Tronstad, 2015). Of these, invasive yellow flag iris comprised $15-24 \%$ of the plant communities sampled. Yellow flag iris may limit the populations in the river because this invasive plant can reduce algal growth on its leaves by $76 \%$ (Shan et al., 2015) and yellow flag iris extracts can kill aquatic insects (Ahmed and El Hamshary, 2005).

\section{Conclusions}

Managers interested in monitoring changes in invertebrate assemblages and comparing results to other aquatic ecosystems should consider using fixed-area samplers (e.g., Hess) rather than artificial substrate samplers (e.g., HD). HD sampling provides a biased perspective of ecosystems with fewer taxa observed and inflated densities of others (i.e., Ephemeroptera). For the Niobrara River and AGFO, the question of which method to use going forward, like many management areas, is complicated by a long-term (1996-2009) monitoring dataset generated with HD samplers. In this study, we provided empirical evidence that, at least for the Niobrara River, making the switch from HD to Hess sampling will provide a more accurate representation of the invertebrate community, use fewer resources, and will not significantly alter long-term trends established through HD sampling from 1996 to 2009. Measuring an accurate baseline is vital when estimating the effects of invasive species, designing conservation plans, or predicting the implications of large-scale environmental stressors such as climate change. Ultimately, biomonitoring goals, stream ecosystem characteristics, and the presence (or absence) of long-term data should dictate what sampling method to use.

\section{Supplementary Material}

\section{Supplementary file supplied by authors.}

The Supplementary Material is available at http://www.kmaejournal.org/10.1051/kmae/2017020/olm.

Acknowledgements. We thank Bryan Tronstad, Hunter McFarland, Oliver Wilmot, Ken Brown, Cody Bish, Marlis Hinckley, Kyle Hack, and Tighe Jones for field and laboratory assistance. We are grateful to Sarah Wakamiya, Patty Bean, Kristina Fox, Mike Benner, Gina Hadean, Bob Manasek, and James Hill of the NPS for their help with logistics and fieldwork. We extend a special thanks to Marcia Wilson at the Northern Great Plains Network Inventory and Monitoring Program for her support. We thank Joe Giersch for his assistance making a map of sampling localities, Lynn Hotaling for comments that improved this manuscript, and Bob Hall and Ken Gerow for their statistical input.

\section{References}

Ahmed A, El Hamshary E. 2005. Larvicidal, miracidiacidal and cercaricidal activities of the Egyptian plant, Iris pseudacorus. $J$ Egypt Soc Parasitol 35: 41-48.

Bates D, Maechler M. 2010. Matrix: sparse and dense matrix classes and methods. R package, version 0999375-43.

Benjamini Y, Hochberg Y. 1995. Controlling the false discovery rate: a practical and powerful approach to multiple testing. J R Stat Soc B 57: 289-300.

Blocksom KA, Flotemersch JE. 2005. Comparison of macroinvertebrate sampling methods for nonwadeable streams. Environ Monit Assess 102: 243-262.

Bowles DE, Peitz DG, Cribbs JT. 2013. Aquatic invertebrate community structure in the Niobrara River, Agate Fossil Beds National Monument, Nebraska, 1996-2009. Great Plains Res 23: $1-10$.

Cairns J, Pratt JR. 1993. A history of biological monitoring using benthic macroinvertebrates. In: Rosenberg DM, Resh VH, eds. Freshwater biomonitoring and benthic macroinvertebrates. New York: Chapman \& Hall, pp. 10-27. 
Canton SP, Chadwick JW. 1983. Aquatic insect communities of natural and artificial substrates in a montane stream. J Freshw Ecol 2: $153-158$.

Carpenter S, Kitchell JF, Hodgson JR, et al. 1987. Regulation of lake primary productivity by food web structure. Ecology 68 : 1863-1876.

Carter JL, Resh VH. 2001. After site selection and before data analysis: sampling, sorting, and laboratory procedures used in stream benthic macroinvertebrate monitoring programs by USA state agencies. JN Am Benthol Soc 20: 658-682.

Czerniawska-Kusza I. 2004. Use of artificial substrates for sampling benthic macroinvertebrates in the assessment of water quality of large lowland rivers. Pol J Environ Stud 13: 579-584.

De Pauw N, Roels D, Fontoura AP. 1986. Use of artificial substrates for standardized sampling omacroinvertebrates in the assessment of water quality by the Belgian Biotic Index. Hydrobiologia 133: 237-258.

Galat DL, Berry Jr CR, Peters EJ, White RG. 2005. Missouri river basin. In: Benke AC, Cushing CE, eds. Rivers of North America. New York, USA: Elsevier Inc., pp. 427-480.

Henderson, B. 2006. Exploring between site differences in water quality trends: a functional data analysis approach. Environmetrics 17: $65-80$.

Hester FE, Dendy J. 1962. A multiple-plate sampler for aquatic macroinvertebrates. Trans Am Fish Soc 91: 420-421.

Holt C, Pfitzer D, Scalley C, Caldwell B, Capece P, Batzer D. 2015. Longitudinal variation in macroinvertebrate assemblages below a large-scale hydroelectric dam. Hydrobiologia 755: 13-26.

Jackson JK, Füreder L. 2006. Long-term studies of freshwater macroinvertebrates: a review of the frequency, duration and ecological significance. Freshwater Biol 51: 591-603.

Jackson ST, Betancourt JL, Booth RK, Gray ST. 2009. Ecology and the ratchet of events: climate variability, niche dimensions, and species distributions. Proc Natl Acad Sci USA 106: 19685-19692.

Johnson RK, Wiederholm T, Rosenberg DM. 1993. Freshwater biomonitoring using individual organisms, populations, and species assemblages of benthic macroinvertebrates. In: Freshwater biomonitoring and benthic macroinvertebrates. New York: Chapman \& Hall, pp. 40-158.

Legendre P, Legendre L. 1998. Numerical ecology. New York, USA: Elsevier Inc.

Letovsky E, Myers IE, Canepa A, McCabe DJ. 2012. Differences between kick sampling techniques and short-term Hester-Dendy sampling for stream macroinvertebrates. Bios 83: 47-55.

Macanowicz N, Boeing WJ, Gould WR. 2013. Evaluation of methods to assess benthic biodiversity of desert sinkholes. Evaluation 32 : 1101-1110.

Mazor RD, Purcell AH, Resh VH. 2009. Long-term variability in bioassessments: a twenty-year study from two northern California streams. Environ Manage 43: 1269-1286.

McCabe DJ, Hayes-Pontius EM, Canepa A, Berry KS, Levine BC. 2012. Measuring standardized effect size improves interpretation of biomonitoring studies and facilitates meta-analysis. Freshw Sci 31: $800-812$.
Merritt RW, Cummins KW, Berg MB. 2008. An introduction to the aquatic insects of North America. Dubuque, IA: Kendall/Hunt Publishing Company.

Oksanen J, Kindt R, Legendre P, et al. 2007. The vegan package. Community ecology package 10 .

Ramsay JO. 2006. Functional data analysis. Encyclopedia of statistical sciences. New Jersey, USA: John Wiley \& Sons.

Rosenberg DM, Resh VH. 1993. Freshwater biomonitoring and benthic macroinvertebrates. New York: Chapman \& Hall.

Shan Y, Wang Z, Luo X, Zheng Z. 2015 Allelopathic inhibition effect of four aquatic macrophytes on Microcystic aeruginosa growth. Fresenius Environ Bull 24: 4025-4033.

Shaw DW, Minshall GW. 1980. Colonization of an introduced substrate by stream macroinvertebrates. Oikos 34: 259-271.

Shelton JM, Samways MJ, Day JA. 2015. Non-native rainbow trout change the structure of benthic communities in headwater streams of the Cape Floristic Region, South Africa. Hydrobiologia 745: 1-15.

Smith DG. 2001. Pennak's freshwater invertebrates of the United States: Porifera to Crustacea. New York, USA: John Wiley \& Sons. Spurgeon JJ, Stasiak RH, Cunningham GR, Pope KL, Pegg MA. 2014. Status of native stream fishes within selected protected areas of the Niobrara River in western Nebraska. Great Plains Res 24: 71-78.

Surber EW. 1936. Rainbow trout and bottom fauna production in one mile of stream. Trans Am Fish Soc 66: 193-202.

Thien SJ. 1979. A flow diagram for teaching texture by feel analysis. J Agron Educ 8: 54-55.

Thorp JH, Covich AP. 2009. Ecology and classification of North American freshwater invertebrates. New York, USA: Academic Press.

Tronstad LM. 2012. Aquatic invertebrate monitoring at Agate Fossil Beds National Monument: 2010 annual report. Natural Resource Technical Report NPS/NGPN/NRTR-2012/654. Fort Collins, Colorado: National Park Service. Available at: http://www.uwyo. edu/wyndd/_files/docs/reports/wynddreports/u12tro04wyus.pdf.

Tronstad LM. 2015. Aquatic invertebrate monitoring at Agate Fossil Beds National Monument: 2014 annual report. Natural Resources Technical Report.

Tronstad LM, Hall Jr RO, Koel TM, Gerow KG. 2010. Introduced lake trout produced a four-level trophic cascade in Yellowstone Lake. Trans Am Fish Soc 139: 1536-1550.

Waters TF. 1969. Subsampler for dividing large samples of stream invertebrate drift. Limnol Oceanogr 14: 813-815.

Waters TF, Knapp RJ. 1961. An improved stream bottom fauna sampler. Trans Am Fish Soc 90: 225-226.

Wickham H. 2011. The split-apply-combine strategy for data analysis. J Stat Software 40: 1-29.

Wilmot O, Tronstad L, Hall R, Koel T, Arnold J. 2016. Lake troutinduced spatial variation in the benthic invertebrates of Yellowstone Lake. Park Sci 32: 25-35.

Wilson KA, Magnuson JJ, Lodge DM, et al. 2004. A long-term rusty crayfish (Orconectes rusticus) invasion: dispersal patterns and community change in a north temperate lake. Can J Fish Aquat Sci 62: $2255-2266$.

Cite this article as: Tronstad LM, Hotaling S. 2017. Long-term trends in aquatic ecosystem bioassessment metrics are not influenced by sampling method: empirical evidence from the Niobrara River. Knowl. Manag. Aquat. Ecosyst., 418, 28. 